\title{
Household Solid Waste Generation and Stakeholders' Attitude towards its Management in Habiganj, Bangladesh
}

\author{
Sumon Banik ${ }^{1}$, M. Mosleh Uddin ${ }^{2}$, S. M. Shamsul Huda ${ }^{1 *}$, Md. Nurul Islam ${ }^{3}$ \\ ${ }^{1}$ Institute of Forestry and Environmental Sciences, University of Chittagong, Chittagong-4331, Bangladesh \\ ${ }^{2}$ Department of Biochemistry and Molecular Biology, Mawlana Bhashani Science and Technology University, \\ Santosh, Tangail-1902, Bangladesh \\ ${ }^{3}$ Department of Pharmacy, Mawlana Bhashani Science and Technology University, Santosh, Tangail-1902, \\ Bangladesh
}

\begin{abstract}
Improper solid waste management is one of the causes of environmental degradation in the developing countries like Bangladesh which results uncollected waste on roads and public places. The objective of the study was to quantify and characterize household solid waste (HSW) as well as to observe the stakeholders' attitudes towards its management in Habiganj for the formulation of frame work for sustainable solid waste management. The study was carried out in Habiganj Municipality with structured questionnaire including some attitudinal questions. Fifty two (52) households were randomly selected and daily wastes from the households were collected, segregated and weighed to quantify and characterize the waste. Waste generation rate was found $1.15 \mathrm{~kg} /(\mathrm{hh} \cdot d)$ and $0.25 \mathrm{~kg} /($ person $\cdot d)$. Generation of waste varied low to high income groups ranging from 0.76 to $1.71 \mathrm{~kg} /(\mathrm{hh} \cdot \mathrm{d})$. Families with more individuals and high educational level generated a larger quantity of solid waste per day. High percentage of organic waste was found in HSW. The majority of the stakeholders (65\%) were taken waste disposal service from a local organization and 55\% of them were found to be satisfied. Most of the respondents (65\%) thought that the municipality is the responsible body for SW management. As the authority couldn't able to manage their wastes properly, the majority of stakeholders felt their interests to pay willingly to community-based organization (CBO) on monthly payment basis. Finally, the authors proposed a framework for sustainable management of solid waste through CBO which will facilitate the responsible policy makers of Bangladesh for planning and executing protocols.
\end{abstract}

Keywords: Solid Waste, Characterization, Generation, Management, Community-based organization

\section{Introduction}

Waste generation increases with population expansion and economic development in most cities of the developing world. Improper solid waste (SW) management is one of the major causes of environmental degradation which causes hazards to inhabitants. Inadequate disposal of solid waste is degrading the environmental quality in numerous ways such as contamination of surface as well as groundwater and soil through direct disposal of wastes or through the leachate, burning of wastes causing air pollution, spreading of diseases through vectors and methane emission through the anaerobic decomposition of wastes [1]. The efficient and effective management of solid waste is a major challenge for the developing countries like Bangladesh.

Bangladesh is a country in South Asia, the eighth most populous country and is among the most densely populated countries in the world [2]. The scenario of SW generation in urban areas of Bangladesh has been changing due to population explosion, urbanization, industrialization, and improving living standards of city dwellers. The unplanned urbanization and massive growing of slums are influenced to SW generation in unidentified quantities in the six major cities such as Dhaka, Rajshahi, Khulna, Chittagong, B arisal and Sylhet in Bangladesh [3]. A massive volume of solid waste is generated every day in the city areas and unfortunately solid waste management (SWM) is being deteriorated day by day due to the limited resources in handling the increasing rate of generating waste [4]. Approximately 6 million tons of wastes are generated in Bangladesh per year [5, 6, and 7]. Dhaka, the capital of Bangladesh annually generates approximately 1.64 million tons of wastes [5], but Dhaka City Corporation (DCC) can pick up and dispose off only $42 \%$ of the total waste generated [8]. The annual per capita generation of MSW ranged from 118.6 to $177 \mathrm{~kg}$ in the country while the average rate was $141.3 \mathrm{~kg}$ as measured in the six major cities [2, 9].

Local Government Bodies (LGB) (City Corporations and municipalities) of Bangladesh are responsible for proper management of SW but they are not able to handle the increasing quantities of waste, which results uncollected waste on roads and public places. However, recently, some NGOs, private and community-based organizations (CBO) work with city authorities. Still, the situation remains unchanged. Source storage and separation are done in an informal and uncontrolled means; hardly $30-40 \%$ of city dwellers practiced it. The CBO has been introduced to collect wastes from generation sources by house-to-house collection systems. The collection efficiency of SW by formal system is only $40-50 \%$ and unsanitary crude dumping method is followed 
for the waste disposal. Another 35-50\% of waste is dumped by self disposal or illegal dumping (uncollected) whereas $10-15 \%$ of waste is recycled by informal system [10]. Primary collection of wastes from source by door to door system might have a beneficial impact if it is done in an efficient way but the coverage of this system is not remarkable. Municipal authorities collect these wastes from secondary disposal site (SDS) and transfer it to the ultimate disposal site (UDS). Actually, the efficiency of the LGB is very disappointing. Conservancy section, in general, is conducting this job along with its other responsibilities such as street sweeping, drain cleaning, street lighting, etc. As a result, required attention and efficient management could not be obtained from the responsible department of LGB as required [11].

Waste audit is one of the vital formulations of management strategy which help to quantify the amount and types of waste being generated by the community or any organization. The structured process facilitates in evaluating alternative equipment needs, systems, management programs and plans, especially with respect to the implementation of disposal, resource and energy recovery options. It depends on a number of factors such as food habit, cultural tradition, socioeconomic and climatic conditions. Refuse characteristics vary not only from the city, but even within the city itself and also seasonally. Quality of refuse should be assessed taking into account the seasonal variation and zonal characteristics. A waste stream assessment is not a one-time activity. As management programs are implemented, periodic waste stream assessments is required to identify successful protocols as well as areas needing improvements [7].

Habiganj is a newly emerging town which is located at the north-eastern part of Bangladesh. The rural and neighboring people are drifting to the Habiganj Municipality from periphery in case of meets the needs of growing demands. The population of the municipality is about 95,000 and the area is about 9.05 square kilometers. With the increasing of population solid waste generation is major concern in Habiganj Municipality. One of the major portions of solid waste generation comes from household activities. As an emerging town it is necessary to investigate the SW generation scenario for developing appropriate SW management system in Habiganj. Therefore, the study was aimed to quantify and characterize residential solid waste generation in Habiganj Municipality as well as to investigate households' awareness and attitude towards its sustainable management. Finally, the authors formulate a framework for sustainable household SW management by CBO in Bangladesh.

\section{Methodology}

The study was carried out in the Habiganj Municipality in Bangladesh. The municipality consists of nine (9) wards. Among nine wards Noa Hati, Ghatia under ward No. 03 and Master Quarter, Raj Nagar under ward No. 07 were selected randomly. Data were collected from three different sources of the study: household questionnaires, survey data and municipality questionnaire survey. Prior to questionnaire survey, a reconnaissance survey was conducted in order to observe the households' socioeconomic status, present practice of solid waste disposal system and to identify various problems created due to the absence of appropriate solid waste collection and their disposal in the study area. Finally, a structured questionnaire was designed, pre-tested, and modified to collect household level data on socioeconomic and daily solid waste traits. In addition the questionnaire included a number of attitudinal questions aimed at examining stakeholders' awareness and attitudes towards solid waste management.

Based on the country's socio-economic status index and households monthly income as well as following [7], the households of selected study area has been categorized into four different income groups (IG): High (H) (monthly income Tk. >50,000) (1USD=Tk.79), Upper middle (UM) (monthly income in between Tk. 30,000-Tk. 50,000), Middle (M) (monthly income in between Tk. 10,000-Tk. 30,000), and Low (L) (monthly income <Tk. 10000)-income groups. Thirteen households were then selected from each stratum through non-proportional random sampling.

A total of fifty two (52) households were studied and household wastes were collected from each household to determine the physical composition of daily household waste by type. During the questionnaire survey, six (6) similar size polythene bags were supplied to each household to give their wastes of different three (3) days. Collected wastes from each poly bags were weighed and recorded. Then the wastes within each bag were segregated and segregated items were weighed separately and recorded. Then the household wastes were categorized into seven different items on the basis of their physical characteristics. The compositions include vegetable \& food stuff, polythene \& plastics, glass \& ceramic, textile, paper, metals, wood \& leaves etc.

\subsection{Household Waste generation}

\section{Results and Discussion}

Solid waste generation by average household (hh) per day (d) has been shown in Fig. 1. The analysis of the 52 sample observations indicates that an average household in Habiganj generated $1.15 \mathrm{~kg}$ of wastes per day. The waste generation rates varies in the different IGs from 0.76 to $1.71 \mathrm{~kg} /(\mathrm{hh} \cdot \mathrm{d})$. The figure showed that the highest waste generation rate was observed in the HIG $(1.71 \mathrm{~kg} /(\mathrm{hh} \cdot \mathrm{d}))$ followed by UMIG $(1.13 \mathrm{~kg} /(\mathrm{hh} \cdot \mathrm{d}))$, 
MIG $(0.99 \mathrm{~kg} /(\mathrm{hh} \cdot \mathrm{d}))$ and LIG $(0.76 \mathrm{~kg} /(\mathrm{hh} \cdot \mathrm{d}))$. Household waste generation rate per household per day increased from LIG to HIG in a sequential stratification. From the study, it can be revealed that the more is the income of the households, the more is the purchasing power and the more is the waste generation rate. In 2008, our research group was also carried out almost similar types of study on solid waste generation at Rahman Nagar residential area (population in 2006: 3500) of Chittagong district in Bangladesh [7]. They reported that different socioeconomic groups (SEG) have an influence on MSW generation in Bangladesh. It was presented that low SEG (monthly income < BDT 5000 where US\$1 = BDT 70) generated $0.36 \mathrm{~kg} /(\mathrm{hh} . \mathrm{d}$ ) MSW; whereas the lower middle (monthly income between BDT 5000 and BDT 10,000), middle (monthly income between BDT 10,000 and BDT 20,000), upper middle (monthly income between BDT 20,000 and BDT 50,000), and high SEG (monthly income above BDT 50,000) generated 0.89, 0.97, 1.10, and $3.15 \mathrm{~kg} /(\mathrm{hh} . \mathrm{d}$ ) MSW, respectively. However, the present outcomes of the study area varied from the value that was recorded by [7], but the trend of gradual increase of waste generation among the IGs was found to be similar.

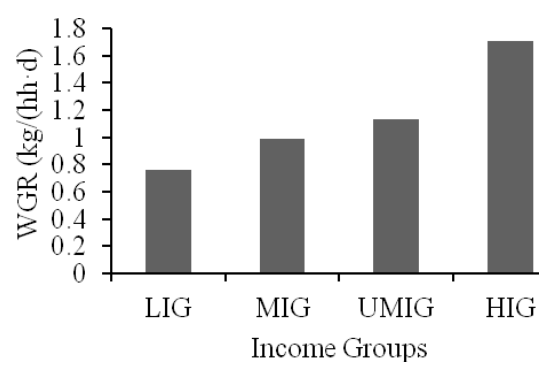

Fig. 1: Solid waste generated by average household per day by different income groups

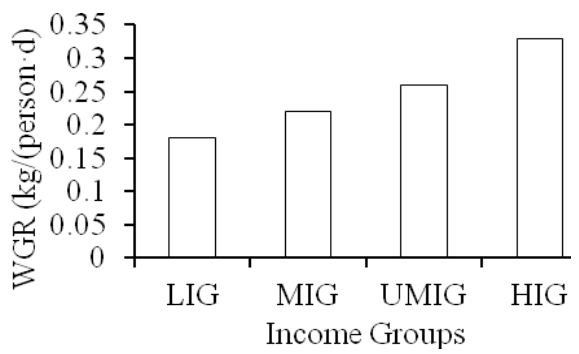

Fig. 2: Solid waste generated per person per day by different income groups

Note: $\mathrm{HIG}=$ High income group $(\mathrm{HIG}), \mathrm{UMIG}=$ Upper middle income group, $\mathrm{MIG}=$ Middle income group and LGI= Low income groups, hh=household and $\mathrm{d}=$ day

Figure 2 showed that the daily solid waste generation rate by a person also increased gradually from LIG to HIG. The average waste generation rate (WGR) of by a person was $0.25 \mathrm{~kg} /$ (person·d). According to the study, the person whose income was high; generated high amount of waste compare to other earning groups. The amount of waste was $0.33 \mathrm{~kg} /$ (person·d) in HIG followed by $0.25 \mathrm{~kg} /($ person.d) in UMIG, 0.22 $\mathrm{kg} /$ (person. $\mathrm{d}$ ) in MIG and $0.18 \mathrm{~kg} /$ (person $\cdot \mathrm{d}$ ) in LIG. According to this study, it is estimated that almost 25,000 $\mathrm{kg}$ of household solid waste was generated daily in Habiganj. However [12] reported that the residential waste generation rate in all the metropolitan cities of Bangladesh was $0.15 \mathrm{~kg} /($ person $\cdot \mathrm{d})$. But, on the contrary, [1] reported that the urban solid waste generation rate was $0.5 \mathrm{~kg} /($ person $\cdot \mathrm{d}$ ) but it is forecasted that it will increase to $0.6 \mathrm{~kg} /($ person $\cdot \mathrm{d})$ in the 2025 [10]. According to [5], the estimated waste generation rate in six major urban areas of Bangladesh: Dhaka, Chittagong, Rajshahi, Khulna, Sylhet, and Barisal was 0.56, 0.48, 0.30, 0.27, 0.30, and $0.25 \mathrm{~kg} /$ (person. $\mathrm{d}$ ), respectively The outcomes of the present study was agreed to [7]. Conversely, according to their article, the WGR per person among the SEG varied: low SEG generate $0.08 \mathrm{~kg} /($ person·d); however the lower middle, middle, upper middle, and high SEG generate $0.20,0.17,0.18$ and $0.55 \mathrm{~kg} /(\mathrm{person} \cdot \mathrm{d})$ respectively [7].

On the other hand, household solid waste generation has been also affected by family size and educational status. The relationships between family size or educational status and generated waste have been presented in fig. 3 and 4 respectively. The quantity of generated waste was linearly increased from less to high family members. Family size with more than 8 persons generated $1.7 \mathrm{~kg}$ waste daily whereas family members in between 1 to 3 generated average $0.5 \mathrm{~kg} / \mathrm{d}$ (Fig. 3 ). 


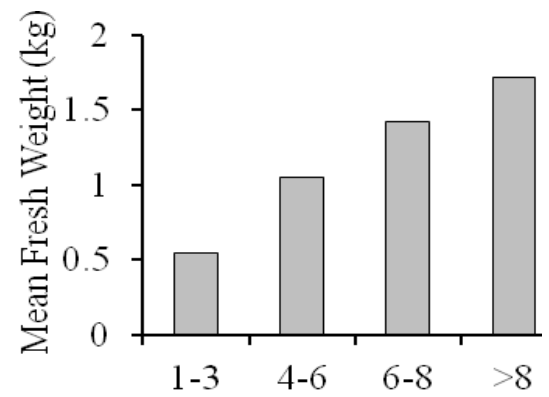

Family size (person/hh)

Fig. 3: Generation of Solid waste based on family size of household

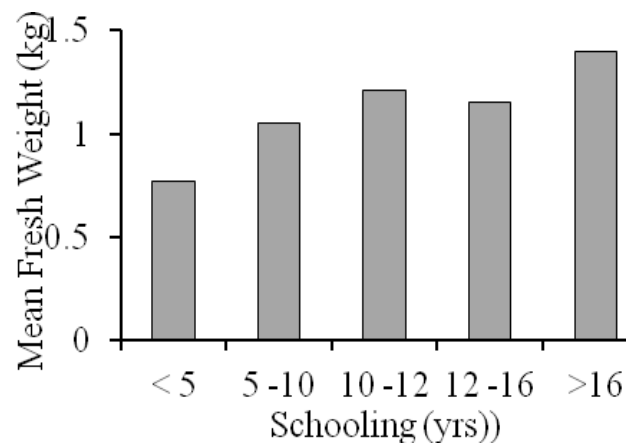

Fig. 4: Generation of Solid waste based on average years of schooling of household

The education level (average number of years in school) of the family had positive relationship with the generation of SW. This reveals that the higher the level of education of the family member, the larger the quantity of SW generated each day. Family member more than 16 years of schooling generated waste $1.4 \mathrm{~kg} / \mathrm{d}$ whereas in less than 5 years of schooling, it was $0.55 \mathrm{~kg} / \mathrm{d}$ (Fig. 4). [7, 13] reported that a number of socioeconomic traits (like income, family size, employment, and education) were positively and significantly correlated with waste generation. [13] was performed their studies on municipal solid waste in Kuwait and recorded that the childless couples produced more than $3 \mathrm{~kg}$ of solid waste per day. On the other hand, families with 8 persons or more generated more than 4 times of waste per day.

\subsection{Physical composition of household solid waste}

Physical composition is important to characterize and classify the MSW for its proper management. Composition of solid waste depends upon a number of factors such as food habits, cultural traditions, socioeconomic status and climatic condition [5]. Figure 5 indicates the physical composition of SW varying with different IGs. All of the seven different items of waste (viz. vegetables \& food waste, wood \& leaves, textile, polythene \& plastics, paper, glass \& ceramic and metals) segregated during the study varied considerably among the IGs. Vegetable/food waste was contributed the highest percentage (around 90\%) whereas polythene and plastic was $4 \%$ and textile as well as glass and ceramic was the lowest. Wood and lather as well as metals were found to be at the same percent $(2 \%)$.

The percentage of vegetable/food waste was found to be the highest in all of the IGs. Among them, both UMIG and MIG were the highest (90\%) and HIG as well as LIG were the lowest. On the other hand HIG generated more polythene and plastic materials $(6 \%)$ than other IGs. In the case of paper, the highest percentage (4\%) was recorded in LIG and the lowest $(2 \%)$ in both HIG and UMIG. Textile, glass and ceramic items generated same least percentages $(1 \%)$ by all the IGs. The highest percentages of wood and leaves materials were generated by LIG (3\%) followed by MIG (2\%), UMIG (1\%) and HIG (1\%) (Fig. 5).

From Fig. 5 it is also apparent that the HSW generated in the study are mostly compostable. The figure showed that $91 \%$ of the total wastes were vegetables \& food waste $(89 \%)$, and wood \& leaves $(2 \%)$ together, which are biodegradable. Only $9 \%$ of the segregated wastes (i.e. polythene \& plastics, paper, textile, glass \& ceramic and metals) were non-compostable but recyclable. [5] recorded that the SW in urban areas were mostly compostable which is account for $69-77 \%$ in Bangladesh. [7] found that $66 \%$ of the HSW was compostable in nature in Rahman Nagar residential area of Chittagong, Bangladesh. Organic fractions $(\geq 69 \%)$ were found to be the largest contributors of MSW in the major cities of Bangladesh [9]. 


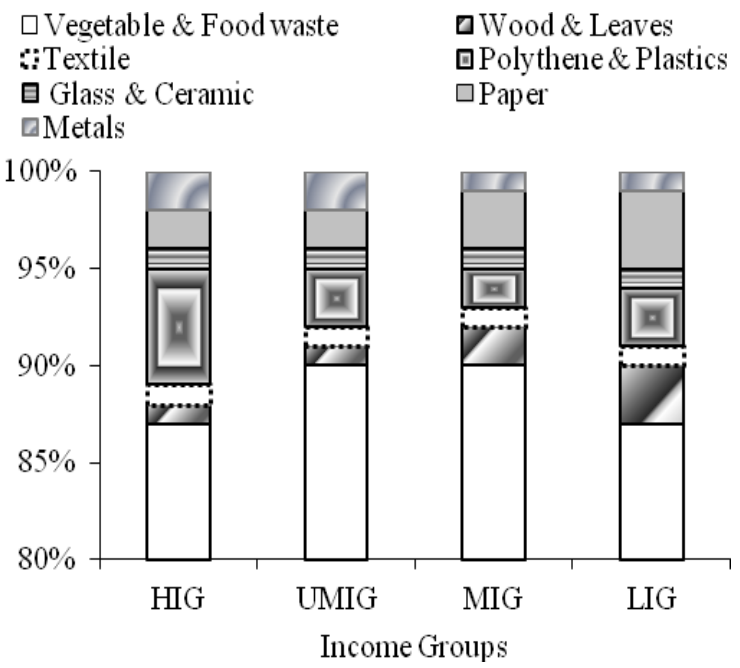

Fig. 5: Physical composition of household solid waste at different income groups

Note: $\mathrm{HIG}=$ High income group $(\mathrm{HIG}), \mathrm{UMIG}=$ Upper middle income group, $\mathrm{MIG}=$ Middle income group and LGI $=$ Low income group

Karak et al. [2] mentioned that the overall socioeconomic condition of the country is probably responsible for the generation of high percentage of organic matter. As from the present study we observed that a huge portion of the HSW was compostable from which needs frequent collection and proper disposal through which we can produce energy from the compostable waste. On the other hand, the recyclable wastes need to recycle for the better environment.

\subsection{Present SW management system}

Approximately $25,000 \mathrm{~kg}$ of household solid waste per day is generated in the Habigonj municipality of Bangladesh. There are 2 (two) systems of waste management observed in the study area. One is Formal System, where municipality is responsible for SWM. The system is based on the conventional system of collection-transportation-disposal of waste carried out by the local authorities. In this system the concept of transfer stations, resource recovery, minimization and recycling are absent. The local authority has given some open bins in different distant places where the households disposed their daily waste directly. The authority collected wastes from the bins and picked up in the open truck and finally, disposed the waste to the open disposal site. Table 1 showed the responses of the sample households on frequency of collection of SW. The majority of the respondents (63.5\%) opined that, the municipal authority should need to collect of waste daily. The other respondents thought that the collection frequency could be performed in alternative day $(11.5 \%)$, every two days/week (9.5\%) and irregularly (any day) (15.4\%).

Table 1: Frequency of collection by Municipal authority

\begin{tabular}{|l|l|l|}
\hline Collection Frequency & Frequency & Percent (\%) \\
\hline Daily & 33 & 63.5 \\
\hline Alternative day & 6 & 11.5 \\
\hline Every two days/week & 5 & 9.6 \\
\hline Irregular (any day) & 8 & 15.4 \\
\hline Total & 52 & 100 \\
\hline
\end{tabular}

Another one is the 'Community-based organization'(CBO) that is based on primary solid waste collection by organization of house-to-house waste collection in locality started due to lack of satisfaction with SWM service by LGB. In the study area, a local organization namely "Community Development Committee" (CDC), is responsible for the collection, transportation and disposal of waste. Out of 52 sample households, 34 households ( $65 \%$ of the total sample household) were taking the private service from the local waste management initiative. The committee hired the laborers and they collected wastes from door to door daily. The households who took the service, the waste collectors collect their wastes from them. Among the households about $55 \%$ were fully satisfied with the service and $35 \%$ were satisfied to some extent and the rest $10 \%$ were not satisfied. Households who are satisfied to some extent and unsatisfied, they argued that they took the service only because there is no other alternative and lack of sufficient number of covered dustbin. 
Table 2: Response rates on Willingness to pay (WTP) by the respondents

\begin{tabular}{|l|l|l|l|l|l|}
\hline Income Group & \multicolumn{4}{|l|}{ Pay value (Taka) } & No. of respondents \\
\hline & $1-20$ & $21-40$ & $41-60$ & $>60$ & \\
\hline LIG & 2 & 3 & 3 & - & $8(44 \%)$ \\
\hline MIG & 1 & 5 & 4 & - & $10(66 \%)$ \\
\hline UMIG & - & 3 & 2 & 1 & $6(75 \%)$ \\
\hline HIG & - & 1 & 5 & 4 & $10(91 \%)$ \\
\hline Total & 3 & 12 & 14 & 5 & 34 \\
& $(8.8 \%)$ & $(35.3 \%)$ & $(41.2 \%)$ & $(14.7 \%)$ & $(65 \%)$ \\
\hline
\end{tabular}

Table 2 shows the willingness to pay for the CBO service. This willingness to pay is varied within different IGs. About $91 \%$ respondents of HIG were interested to pay willing to get the door to door collection; however $44 \%$ of LIG, $75 \%$ of UMIG and $66 \%$ of MIG also felt their curiosity to pay for the service. Among the respondents, $41 \%$ were willed to pay Tk. 41-60 per month, 35\% interested to pay Tk. $21-40,15 \%$ to pay above Tk. 61 and the rest (9\%) to pay Tk. 1-20 per month. Presently, CDC is taking a fee Tk. 50 per month for door to door collection service and the households were habituated to pay the amount.

\subsection{Stakeholders' approach towards SWM}

Households can play an important key for the proper management of HSW. The responses of the sample household to a number of attitudinal questions are shown in Table 3. So far the largest percentages of the sample household $(65.4 \%)$ were of the opinion that the responsible body for SW management lies entirely on the municipality. Only $15.4 \%$ opined that local organization was responsible for SW management. The rests $(19.2 \%)$ thought that the households had their self role in managing their wastes. While asking the respondents regarding the place to which they dumped their waste. A large percentage of the sample households $(65.4 \%)$ were found to dispose their waste through the waste collector and $15.4 \%$ of the households disposed their waste in covered dustbin. About $11.5 \%$ of the households disposed their waste to open places and $7.7 \%$ threw the waste directly into drains (Table 3).

Table 3: Frequency distribution and sample stakeholders' opinions on residential solid waste

\begin{tabular}{|c|c|c|c|}
\hline Variable name & Frequency & Percent $(\%)$ & Cumulative percent $(\%)$ \\
\hline \multicolumn{4}{|c|}{ Whose responsibility is the household soild waste management? } \\
\hline Municipality & 34 & 65.38 & 80.77 \\
\hline Local organization & 8 & 15.39 & 15.39 \\
\hline Self-role & 10 & 19.23 & 100 \\
\hline \multicolumn{4}{|c|}{ How do the households dispose their wastes? } \\
\hline To waste collector & 34 & 65.38 & 65.38 \\
\hline Covered dustbin & 8 & 15.39 & 80.77 \\
\hline Throwing into drain & 4 & 7.69 & 88.46 \\
\hline Open dump & 6 & 11.54 & 100 \\
\hline \multicolumn{4}{|c|}{ What are the households self role in waste management? } \\
\hline Collection & 32 & 61.54 & 61.54 \\
\hline Segregation & 9 & 17.31 & 78.85 \\
\hline Reuse/recycle & 5 & 9.61 & 88.46 \\
\hline Disposal & 6 & 11.54 & 100 \\
\hline \multicolumn{4}{|c|}{ Which one of the following $S W$ nuisance you face most? } \\
\hline Bad odor & 15 & 28.85 & 28.85 \\
\hline Blockage of drain & 19 & 36.54 & 65.39 \\
\hline Disease vector & 7 & 13.46 & 78.85 \\
\hline Fly Nuisance / Mosquitoes & 11 & 21.15 & 100 \\
\hline \multicolumn{4}{|c|}{ Do you concern about the SWM? } \\
\hline Concerned & 18 & 34.62 & 34.62 \\
\hline Somewhat concerned & 19 & 36.54 & 71.16 \\
\hline Slightly concerned & 11 & 21.15 & 92.31 \\
\hline Not at all & 4 & 7.69 & 100 \\
\hline
\end{tabular}

The respondents were asked regarding their self-role on waste management. A large percentage of sample stakeholders $(61.5 \%)$ mentioned that their role on waste management lies only within the collection system. About $17.3 \%$ showed their interests in segregation their waste items whereas $9.6 \%$ of households opined to reuse their waste to minimize their wastes prior to disposal or to sell to potable recycle item collectors. The rests $(11.5 \%)$ felt their interests to directly dispose their waste to the bin or to the waste collector.

The responses of the sample households with regard to the nuisance of SW disposal had the following outcomes. All the sample stakeholders were asked to mention the severe problem relate to SWM in the study area. Majority of the respondents informed blockage of drain (36\%) and bad odor $(29 \%)$ are the main problem relate to SWM in study area. Some other respondents stated fly nuisance and mosquitoes were also create problem whose percentage lies $(21 \%)$, and disease vectors about $13 \%$. While a question regarding consciousness 
of waste management was asked to the respondents, only $34.6 \%$ opined that they were concerned. Another $36.5 \%$ were found to be somewhat concerned whereas $21 \%$ were slightly concerned. About $7.8 \%$ were not totally concerned regarding SW management.

Improper management of SW creates environmental problems, mainly in developing countries like Bangladesh. The cities of developing countries have lack of institutional, financial, technical, regulatory, knowledge, and public participation regarding SW management [14]. Proper SWM is not only an environmental issue, but also a sociopolitical problem in developing countries [2]. Proper management of solid waste is a very difficult task for any organization or authorities if the community people do not associate with the activities of the management process. The SWM by local body can never be successful without active community participation and the LGB needs effective use of investments of their funds; they should involve the community in all programs through a consultative process and a variety of other communication approaches [10]. In Bangladesh, the LGB of Bangladesh is responsible for SWM as the authorities are collecting conservancy tax from the owners of the holdings under their jurisdiction. Unfortunately, waste is disposed in low-lying areas within or outside their boundaries applying open crude dumping method without any environmental protection. Thus it is essential to develop waste management strategy through CBOs in a sustainable way for Bangladesh.

\section{A proposal for sustainable SWM in Bangladesh}

Although the local government authorities are usually liable for solid waste collection and disposal, but the magnitude of the problem is well beyond the ability of any municipal government to tackle. The authors reported that $55 \%$ of the sample households were satisfied and they had the tendency to willing to pay to the community based organization. In another study of our research group also found almost similar results which were carried out in a residential area of Chittagong City where more than $60 \%$ of the sample dwellers were satisfied to local waste management initiative [7]. The study recommends initiation and enhancement of CBO for solid waste management practices at each and every location in the municipalities with close collaboration of government.

Based on the outcomes of the present as well as previous study [7] and so far literature reviewed [1, 15, and 16], the authors proposed the following waste management strategy through CBO as shown in Fig. 6. According to proposed framework, the waste collectors, hired by $\mathrm{CBO}$ will collect the wastes from door to door from respective dwellers. They'll also sort all wastes and categorize the waste into recyclable, organic and others. All the wastes will be transport to the separation center/ transfer station. The purpose of the center/station is not only to segregate and compress the waste but also shredding and pulverizing the organic waste to ensure efficient transport to recycle center and also organic waste to composting site. The compost fertilizer can be sold to the dwellers or to the farmers for using in the agricultural field or to the plantation site. Finally, the residues will be burnt in a controlled manner and dispose the ashes to the landfill site.

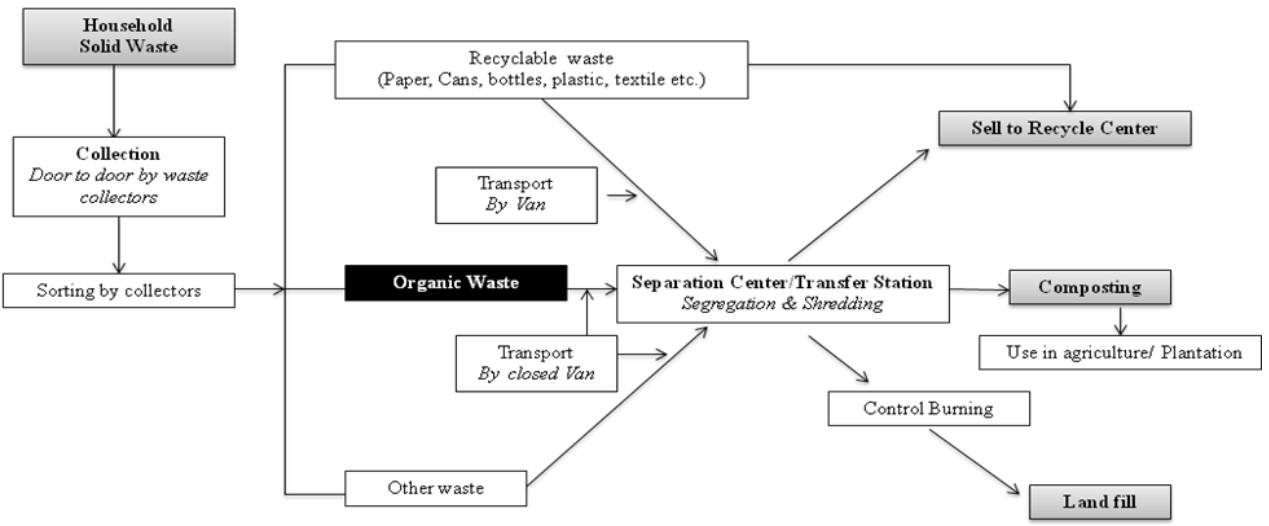

Figure 6: Proposed framework for sustainable solid waste management in Bangladesh by CBO

\section{Conclusions}

Solid waste today is considered to be one of the most immediate and serious environmental problems regarding its production and disposal in developing countries like Bangladesh. With the increase of population in Bangladesh the solid waste generation is also increasing that is the major concern for sustainable environment. Habiganj Municipal area is one of the small town in Bangladesh where a significant amount of solid waste generation by the large number of population increasing day by day.The objective of the present study was to assess the household SW generation and to observe the stakeholders' approaches towards its management in Habiganj municipality for developing a strategy for sustainable management. The outcomes of the study indicated that the quantity of waste generated $1.15 \mathrm{~kg} /(\mathrm{hh} \cdot \mathrm{d})$ and $0.25 \mathrm{~kg} /($ person $\cdot \mathrm{d})$. The generated 
waste varied low to high income groups ranging from 0.76 to $1.71 \mathrm{~kg} /(\mathrm{hh} \cdot \mathrm{d})$. Generation of household solid waste was found to be positive relationship with family size, and educational level. Families with more individuals and high educational level generated a larger quantity of solid waste per day. It indicates that while developing policies for SW management, improving the general public's awareness should be given a high priority of the responsible policy makers. The distribution of daily household solid waste by type was vegetable/foodstuff, $89 \%$, paper materials; polythene and plastic, 4\%; paper, 3\%; wood and lather as well as metals individually $2 \%$ )and others (textile and ceramic), $2 \%$.

The majority of the sample stakeholders in the study area (65\%) were taken the CDC service and $55 \%$ of them were found to be satisfied. Most of the households $(65 \%)$ thought that the municipality is the responsible body for SW management. On the other hand, a large percentage of the sample households $(65.4 \%)$ were interested to give their waste to the waste collector. As the municipality couldn't able to manage the SW properly, they were satisfied to CDC and the maximum households felt their curiosity to pay willingly on monthly payment basis; the study proposed a framework for sustainable management of solid waste through community-based organization. The authors thought that the framework will facilitate the responsible policy makers of Bangladesh at Government level for planning and executing guidelines for proper management of SW to achieve the sustainable development goal.

\section{References}

[1] C. Zurbrügg. Urban Solid Waste Management in Low-Income Countries of Asia. How to Cope with the Garbage Crisis: Scientific Committee on Problems of the Environment (SCOPE) Urban Solid Waste Management Review Session, Durban, South Africa. 2002. pp. 1-13.

[2] T. Karak , R. M. Bhagat and P. Bhattacharyya. Municipal Solid Waste Generation, Composition, and Management, The World Scenario Critical Reviews in Environmental Science and Technology, 42, 2012, 1509-1630.

[3] M. Salequzzaman, M. Awal, M. Alam. Willingness to pay: community based solid waste management and its sustainability in Bangladesh, Proc. of the International Conf. "The Future is Here”, RMIT, Melbourne, Victoria, January 15-19, 2001.

[4] K. M. Bahauddin, and M. H. Uddin, Prospect of Solid Waste Situation and An Approach of Environmental Management Measure (EMM) Model for Sustainable Solid Waste Management: Case Study of Dhaka City, Journal of Environmental Science and Natural Resources, 5(1), 2012, 99-111.

[5] I. Enayetullah, A. H. M. M. Sinha, S. S. A. Khan, Urban Solid Waste Management Scenario of Bangladesh: Problems and Prospects. Waste Concern Technical Documentation, Dhaka, Bangladesh, 2005, 18p.

[6] G. M. J. Hasan, M.A.I. Chowdhury, Municipal waste management and environmental hazards in Bangladesh. Pakistan Journal of Biological Science, 8 (6), 2005, 921-928.

[7] M. Sujauddin, S. M. S. Huda, A.T.M.R. Hoque, Household solid waste characteristics and management in Chittagong, Bangladesh. Waste Management, 28(9), 2008, 1688-1695.

[8] M. Salequzzaman, M.G. Murtaza, M. Saroar. Evaluation Study on Municipal Solid Waste Management Project in Khulna City, PRODIPAN, Shaheb Bari Road, Khulna 9203, Bangladesh, 1998.

[9] A. Ahsan. Generation, composition and characteristics of municipal solid waste in some major cities of Bangladesh. Master's thesis, Department of Civil Engineering, Khulna University of Engineering and Technology, Bangladesh, 2005.

[10] Anon, Country Paper Bangladesh. SAARC workshop on Solid waste Management. Department of Environment (DOE), Waste Concern, ITNBUET, Dhaka, Bangladesh, 2004,19 pp.

[11] WasteSafe. Integrated Management and Safe Disposal of Municipal Solid Waste in Least Developed Asian Countries: A feasibility study, in M. Alamgir; C. McDonald, K.E. Roehl and M. Ahsan (Eds), KUET, Bangladesh, 2005.

[12] World Bank. What a Waste: Solid Waste Management in Asia, Washington DC, USA, 1999, p. 43.

[13] P. A. Koushiki, J. M. Alhumoud, U. Al-Duaij. Municipal solid waste in Kuwait: Trends, and attitudes on collection, separation and willingness to pay, Kuwait J. Sci. Eng. 31(2), 2004, 173-188.

[14] U. N. Ngoc, and H. Schnitzer. Sustainable solutions for solid waste management in Southeast Asian countries, Waste Management. 29, 2009, 1982.

[15] S. Rathi, Alternative approaches for better municipal solid waste management in Mumbai, India. Waste management, 26(10), 2006, 1192-1200.

[16] A. H. M. M. Sinha. Community Based Solid Waste Management Through Public-Private Community Partnerships: Experience of Waste Concern in Bangladesh. Paper presented in 3R South Asia Expert Workshop, Katmandu, Nepal, 2006. 